\title{
Anabases
}

ANABASES Traditions et réceptions de l'Antiquité

$26 \mid 2017$

Varia

\section{Laurent PERNOT, Epideictic Rhetoric, Questioning the Stakes of Ancient Praise}

\section{Catherine Psilakis}

\section{OpenEdition}

\section{Journals}

Édition électronique

URL : http://journals.openedition.org/anabases/6266

DOI : $10.4000 /$ anabases. 6266

ISSN : 2256-9421

\section{Éditeur}

E.R.A.S.M.E.

\section{Édition imprimée}

Date de publication : 1 novembre 2017

Pagination : 243-245

ISSN : 1774-4296

\section{Référence électronique}

Catherine Psilakis, "Laurent PERnOt, Epideictic Rhetoric, Questioning the Stakes of Ancient Praise », Anabases [En ligne], 26 | 2017, mis en ligne le 01 novembre 2017, consulté le 20 janvier 2021. URL: http://journals.openedition.org/anabases/6266 ; DOI : https://doi.org/10.4000/anabases.6266

Ce document a été généré automatiquement le 20 janvier 2021.

(c) Anabases 


\title{
Laurent PERNOT, Epideictic Rhetoric, Questioning the Stakes of Ancient Praise
}

\author{
Catherine Psilakis
}

\section{RÉFÉRENCE}

Laurent PERNOT, Epideictic Rhetoric, Questioning the Stakes of Ancient Praise, Austin, University of Texas Press, 2015, 182 p., 13, 37 dollars / ISBN 978-1-4773-1133-2.

1 Pour qui s'intéresse à la rhétorique de l'éloge, les travaux de Laurent Pernot constituent aujourd'hui une référence qu'il n'est plus nécessaire de présenter ( $L a$ rhétorique de l'éloge dans le monde gréco-romain, L. Pernot, Paris, Institut d'études Augustiniennes, 1993). Ce nouvel ouvrage est issu d'un séminaire tenu en mai 2012 à la Rhetoric Society of America à Philadelphie. Il s'agit une synthèse sur la rhétorique épidictique qui, sans viser à l'exhaustivité, bénéficie toutefois des avancées les plus récentes des études consacrées à la rhétorique. Dans une courte préface, l'auteur rappelle toute la difficulté d'instituer la rhétorique de l'éloge en objet d'étude historique et le relatif désintérêt pour ce champ de la rhétorique jusque dans les années 1980. L'ouvrage de 166 pages se compose de quatre chapitres suivis d'une conclusion, d'un appareil de notes par chapitre, d'une bibliographie et d'un index général.

2 Le premier chapitre "The unstoppable rise of Epideictic» définit ce que l'auteur considère comme la rhétorique de l'éloge au sein de la cité athénienne après les guerres médiques jusqu'à sa pratique dans l'empire romain. L'auteur part de l'epitaphios logos, moins une forme littéraire qu'une institution civique, pour mentionner immédiatement les premiers éloges d'un individu avec le discours Evagoras d'Isocrate (365 avant J.-C.). L'étape suivante est naturellement celle de la théorisation aristotélicienne qui fait de la rhétorique épidictique l'un des trois genres rhétoriques aux côtés des genres délibératif et judiciaire. C'est avec l'empire romain que la rhétorique de l'éloge se développe: l'enseignement, la théorisation et la pratique oratoire accompagnent la multiplication des occasions de célébrer des événements familiaux et des séjours, prises de postes, 
départs des empereurs, gouverneurs ou encore des consuls. Les témoignages se multiplient, qu'il s'agisse d'inscriptions, de traités théoriques (Peri epideiktikon de Ménandre le Rhéteur II) et de discours eux-mêmes qui ont été conservés. Sans reprendre dans le détail la démonstration, rappelons que le développement de la rhétorique de l'éloge s'explique en grande partie par son contexte. L'empire romain a su établir une paix durable qui permet la célébration de festivals, de compétitions et de cérémonies privées et publiques. La paix et la prospérité ont également contribué à établir solidement la paideia offertes aux élites. Très actifs dans l'éducation de ces dernières, les sophistes jouent un rôle fondamental dans la diffusion de la pratique de l'éloge.

3 Le deuxième chapitre "The Grammar of Praise» s'intéresse plus en détail à la matière de l'éloge, cet ensemble d'usages et de règles, de vocabulaire et de topoi (lieux communs) qui permettent à l'orateur d'exprimer les valeurs de la société et à l'auditoire de les reconnaître. Après avoir abordé les topoi, l'auteur passe en revue les structures types de l'éloge oscillant entre un récit chronologique et un portrait moral. Initialement élaborés pour l'éloge d'un individu, les théoriciens adaptent les topoi aux différents objets de l'éloge : ainsi les parents deviennent le fondateur dans l'éloge d'une cité. L'auteur s'intéresse aussi à l'hymnos, l'éloge rhétorique consacré à un dieu. Sont ensuite analysés les éloges d'animaux et d'objets inanimés ainsi que la typologie des discours élaborée au fil des siècles. Les tropes et les figures les plus caractéristiques de l'éloge (l'apostrophe, l'hyperbole et la comparaison/métaphore) sont également analysés. L'auteur aborde rapidement le blâme, car il reste davantage un exercice d'école et voit sa pratique sociale fort limitée. Ce n'est pas tant que ce type de discours n'ait pas existé, mais ils ont été beaucoup moins l'objet d'étude et de théorisation.

Le troisième chapitre «Why epideictic Rhetoric» revient sur le rôle de la rhétorique encomiastique et sur les tensions qu'elle peut susciter. L'auteur rappelle le lourd héritage aristotélien qui a influencé la postérité. De fait, ce sont toujours les mêmes reproches d'inutilité et de flatterie qui courent de Thucydide à Platon, de Cicéron à Tacite jusqu'à saint Augustin. Pour établir l'importance sociale de ce genus, l'auteur s'appuie naturellement sur le nombre et la variété des discours, mais également sur les infrastructures des cités de l'empire romain (dans lesquelles de nombreux endroits étaient particulièrement dédiés à la rhétorique encomiastique) et la qualité du public. Il s'agit de discours "autorisés ", que l'orateur ait été choisi par la cité (pourl'epitaphios logos) ou par l'empereur. Même dans les cérémonies privées, les orateurs qui se livraient à la rhétorique de l'éloge répondaient à une sollicitation extérieure. Aux côtés des cérémonies, des portraits, des inscriptions, des acclamations ou encore des décrets honorifiques, les discours de l'éloge jouent pleinement leur rôle au sein de la société. Ils constituent un acte de justice et une obligation. Ils relèvent à la fois du devoir moral et social de l'orateur. L'éloge comporte un message qui confine à l'exhortation aux valeurs communes, une forme de conseil adressé à l'auditoire qui voit dans l'objet de l'éloge un modèle de conduite à tenir. En ce sens, les orateurs contribuent à établir et à consolider des valeurs communes.

et dernier chapitre, «New approaches in epideictic Rhetoric», l'auteur enrichit son analyse grâce aux dernières recherches consacrées à la rhétorique 
: il s'agit de la partie la plus intéressante et sans doute la plus novatrice de l'ouvrage. Premièrement, en empruntant les outils des linguistes et des anthropologues, l'auteur démontre de manière persuasive que les discours de l'éloge possédaient une utilité liée

à leur dimension performative et cérémonielle

: les discours eux-mêmes sont à considérer comme des actes à part entière dans les différentes occasions où ils sont prononcés. Deuxièmement, l'auteur souhaite appliquer

la méthode du «

discours figuré » à la littératureencomiastique afin de mieux cerner les doutes et les critiques envers l'objet de l'éloge qui peuvent affleurer et ainsi mieux saisir la dimension subversive de l'éloge, utilisé dans ce cas comme une arme contre celui à qui les louanges sont initialement destinées. Troisièmement, il s'agit pour l'auteur d'aborder la littérature encomiastique grâce aux outils de la psychologie. Logiquement source de plaisir, l'éloge peut devenir gênant, voire désagréable, lorsqu'il verse dans l'excès ou qu'il est simplement soupçonné de le faire. Quatrièmement, l'auteur attire l'attention sur la dimension religieuse de la rhétorique de l'éloge, en particulier dans les hymnes rhétoriques où l'orateur joue le rôle d'intercesseur entre la divinité et l'auditoire. Il existait de facto une forme rhétorique de l'éloge commune aux païens et aux chrétiens, ce qui autorise l'auteur à aller au-delà des différentes religions pour identifier des formes rhétoriques fondamentales et ainsi établir un nouvel angle d'approche des études consacrées à la religion. Cinquièmement, l'auteur s'appuie sur la comparaison de discours d'époques et de cultures différentes afin de dégager les différences, mais surtout les constantes dans la rhétorique de l'éloge.

L'ouvrage de Laurent Pernot, destiné à un public anglais, a toutes les qualités d'une synthèse scientifique : dans un style clair, les points les plus importants sont évoqués et appuyés par des citations d'auteurs anciens. L'érudition de l'auteur permet d'embrasser la littérature de l'Athènes classique à l'empire romain jusqu'à l'Antiquité tardive. On pourrait toutefois regretter de ne pas avoir accès aux textes en grec et en latin, mais le format exigeait sans doute le recours aux traductions. En dernière instance, le seul reproche que l'on peut formuler envers cet ouvrage concerne le dernier chapitre: il laisse le lecteur quelque peu frustré de ne lire que des pistes esquissées. La dimension linguistique et anthropologique de même que la méthode comparée auraient sans doute mérité un plus long développement. Gageons qu'il sera l'objet d'un nouvel ouvrage que l'auteur consacrera à la rhétorique de l'éloge.

\section{AUTEUR}

\section{CATHERINE PSILAKIS}

Université de Lyon

catherine.psilakis@univ-lyon1.fr 